\title{
Clean fuels synthesis from green hydrogen: a techno-economic comparative analysis
}

\author{
Daria Bellotti ${ }^{*}{ }^{*}$, Massimo Rivarolo ${ }^{1}$, and Loredana Magistri ${ }^{1}$ \\ ${ }^{1}$ Thermochemical Power Group, DIME - University of Genoa, Via Montallegro 1, 16145 Genova, Italy
}

\begin{abstract}
In this paper, two different power-to-fuel solutions for sustainable fuel synthesis are investigated from the energetic, environmental, and economic standpoints. Both the solutions consider a pressurized PEM electrolysis section, fed by renewable sources, where high purity green Hydrogen is produced. Then, two separate processes are investigated for the synthesis of two distinct chemicals. In the first case, the hydrogen is mixed with $\mathrm{CO}_{2}$, sequestered by an industrial plant, and captured a carbon capture system (CCS): the two gases are sent to a pressurized reactor for methanol synthesis. In the second case, the hydrogen is mixed with $\mathrm{N}_{2}$, obtained from an industrial air separation unit (ASU), and sent to a reactor for ammonia synthesis. Both the synthesis processes are performed at high pressures and temperatures, thus a thermodynamic analysis is mandatory in order to calculate the overall efficiencies. In both cases, the power to fuel plants are investigated also in economic terms. Methanol synthesis presents a slightly higher efficiency compared to ammonia, while the two solutions are very similar from the economic standpoint. The sale of the co-produced oxygen allows for an improvement in economic terms for both cases and can be a key point in order to reach economic sustainability, together with the expected reduction in PEM electrolysers capital cost.
\end{abstract}

\section{Introduction}

The world energy demand has increased more and more in the last decades: although in EU the increase is more limited, also thanks to recent EU energy policies, the recent development of many Countries is leading to an important increase in terms of Total Final Consumption worldwide, up to almost 10 Gtep in 2017 [1]. Because of the growing energy demand, carbon dioxide concentration in the atmosphere has increased up to $410 \mathrm{ppm}$ by anthropogenic activities. More than half of total $\mathrm{CO}_{2}$ emissions are related to electricity, heat, and energy sectors, with a historic high of 33.1 Gton in 2018 [1]. In this context, the promotion of Renewable Energy Sources (RES), is a key factor for energy sustainability. The contribution of RES is increasing more and more worldwide. At the European level, the share of electrical energy production by RES has increased from $15 \%$ in 2007 to $29 \%$ in 2017 [1]. According to EU energy policies, the share of renewable energy sources is going to reach $32 \%$ of final energy consumptions in 2030 [2]. Fast growth of RES, in particular not programmable ones as wind and solar, can represent some critical aspects related to their integration in the electrical system, thus requiring new energy storage solutions to increase electrical grids flexibility.

In this context, hydrogen production by water electrolysis employing renewable electricity can represent an interesting solution to store overproduction by RES, at the same time allowing for the synthesis of clean fuel, as investigated by the authors' research group in previous research works [3][4]. However, hydrogen presents some issues related to its storage, transportation, and utilization, due to its low energy density and to the high costs related to its infrastructure, which is still in development [5][6]. Furthermore, the costs of clean $\mathrm{H}_{2}$ production by water electrolysis are still high, even if they are decreasing more and more [7]. Power to Fuel (P2F) systems can represent an interesting solution for the next future, as hydrogen can be produced by water electrolysis fed by RES in a sustainable way and then stored in a more convenient energy carrier, avoiding in this way problems related to hydrogen storage and delivery. Ammonia and methanol are two of the most interesting candidates for the chemical storage of renewable electricity, for several reasons: (i) methanol is liquid at ambient pressure and temperature, ammonia can be easily liquefied (it is liquid at ambient pressure and $-33^{\circ} \mathrm{C}$ ); (ii) their energy

* Corresponding author: daria.bellotti@edu.unige.it 
density is significantly higher than hydrogen; (iii) technologies related to large size synthesis, storage and transportation are present at competitive costs.

Methanol has an LHV of $19.9 \mathrm{MJ} / \mathrm{kg}$ in mass terms and an energy density of $15.7 \mathrm{MJ} / \mathrm{l}$. Methanol can be considered a valuable hydrogen carrier, considering that $1 \mathrm{Nm}^{3}$ of methanol contains about $100 \mathrm{~kg}$ of hydrogen [8][9]. Methanol synthesis was investigated by the authors in previous research works considering the following reaction, which takes places at temperatures of $250-300{ }^{\circ} \mathrm{C}$ and pressures of $50-100$ bar [8][10]:

$$
\mathrm{CO}_{2}+3 \mathrm{H}_{2} \rightarrow \mathrm{CH}_{3} \mathrm{OH}+\mathrm{H}_{2} \mathrm{O} \Delta \mathrm{H}-49.5 \mathrm{~kJ} / \mathrm{mol}(1)
$$

Ammonia is a chemical compound based on nitrogen and hydrogen. Although it is a gas at standard pressure and temperature, its liquefaction is quite easy, as it is liquid at ambient temperature and modest pressure (10 bar) or at ambient pressure and temperature of $-33{ }^{\circ} \mathrm{C}$. Ammonia is considered as one of the most promising energy carriers for hydrogen: a cubic meter of ammonia contains about $145 \mathrm{~kg}$ of $\mathrm{H}_{2}$. In terms of volumetric energy density, liquid ammonia and methanol are very similar, with a value of about $15.7 \mathrm{MJ} / 1$ (for liquid $\mathrm{H}_{2}$ the value is $8.4 \mathrm{MJ} / \mathrm{l}$ ), while its LHV is $22.5 \mathrm{MJ} / \mathrm{kg}$ [9]. Another interesting feature of ammonia is the absence of carbon in its molecule, thus its impact in terms of $\mathrm{CO}_{2}$ emissions in its combustion is zero. Traditionally, ammonia is produced in large plants by the Haber-Bosch process, with the following reaction, which takes place at high pressure and temperature in presence of ironbased catalysers [11]:

$$
\mathrm{N}_{2}+3 \mathrm{H}_{2} \rightarrow 2 \mathrm{NH}_{3} \Delta H=-92 \mathrm{~kJ} / \mathrm{mol}
$$

Both methanol and ammonia can be synthesized starting from hydrogen [12][13]. In traditional industrial plants, hydrogen is produced by coal or natural gas reforming, with a strong impact in environmental terms.

In this paper, the production of the two chemicals, methanol and ammonia, with a clean process, considering green hydrogen production by water electrolysis, is investigated and compared from the technical and economic standpoints. Several research works have been already proposed on the theme of the power-to-fuel process, even by the authors themselves $[14][15][16][17]$. However, the previous works present techno-economic analysis on one of two processes and in a specific case-study [18][19][20][21], or a comparison only based on the energy balance [22].

This works aims at presenting a comparison between the $\mathrm{P} 2 \mathrm{M}$ and $\mathrm{P} 2 \mathrm{~A}$ processes as an alternative solution for renewable energy storage from both the technical and economic points of view, highlighting the pro and cons of both solutions.

\section{Case study}

\subsection{Plant layout}

Figure 1 shows a simplified scheme of the power-toliquid (P2L) plant from clean energy produced by renewable energy, a wind farm in the case under analysis. Hydrogen is produced by a system of commercial large-scale PEM electrolysers, operating at 30 bar. Carbon dioxide and nitrogen necessary for reactions (1) and (2) respectively are purchased by industrial producers at market prices. After compression and heating to bring the reactants at the proper thermodynamic conditions for the reactions (1) and (2), the gas mixtures are sent to the methanol/ammonia synthesis units.

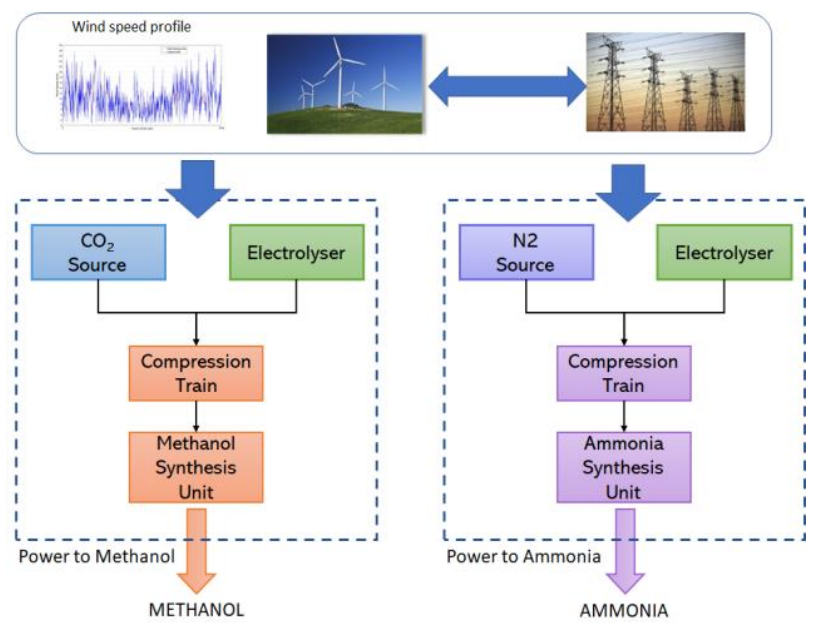

Fig. 1. Power to methanol and power to ammonia layouts

As wind energy availability has a time-dependent and not programmable nature, it is important to determinate the proper size of the PEM electrolysers as a function of the wind farm size as first step of the analysis. This process is mandatory for the coupling of a not programmable RES (i.e. wind and solar) to a system for $\mathrm{H}_{2}$ production by water electrolysis [23].

In the case under analysis, the wind farm is assumed to be composed of $1 \mathrm{MW}$ turbines, with a cut-in speed of $3 \mathrm{~m} / \mathrm{s}$ and a rated speed of $15 \mathrm{~m} / \mathrm{s}$.

Based on the wind speed profile considered in the present work, a single $1 \mathrm{MW}$ turbine produces about $1.48 \mathrm{GWh}$ per year.

On basis of the P2L plant size - wind farm size ratio, and considering the wind production profile, there will be some periods in which wind energy exceeds the plant demand and vice versa. The wind farm is connected both to the P2L system and to the electrical grid: thus, it can exchange with the network, selling and purchasing electricity when required. Figure 2 reports the Grid Energy Exchange as a function of the PEMEL size and the Wind Farm size. The Grid Energy Exchange (GEE) is calculated as follows:

$$
\begin{aligned}
& \text { GEE } \\
& =\text { Wind Energy Surplus sold to the Grid } \\
& \text { - El. Energy purchased from Grid }
\end{aligned}
$$

In the grey region, the GEE value is negative, meaning that the annual amount of electrical energy purchased from the grid is higher than that one sold as wind surplus; in the white area, vice versa. 


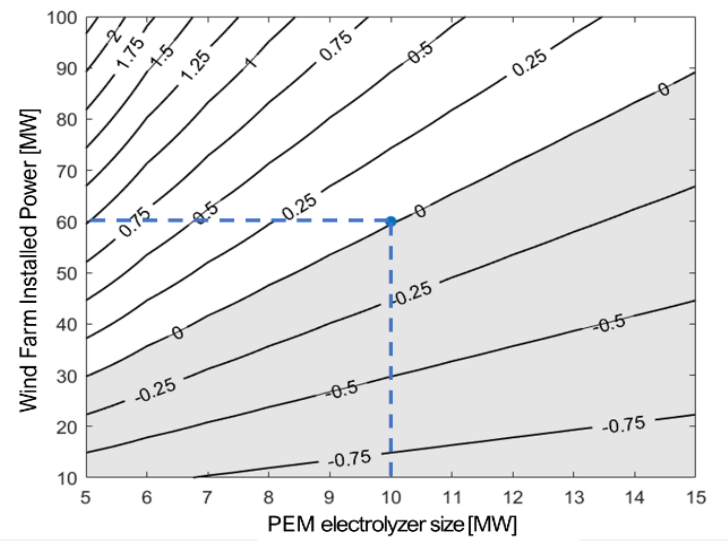

Fig. 2. Hydrogen production system size vs wind farm size

The size of the wind farm is defined on the basis of the "Grid-Balance" principle, according to which the total amount of energy surplus sold to the grid and the amount of energy purchased from the grid is the same. In this sense, the electrical network represents a sort of storage for the wind energy surplus and it is possible to assume that the energy powering the $\mathrm{P} 2 \mathrm{~L}$ is totally renewable. Based on the results of Figure 2, the Grid-Balance is obtained for a Wind Farm - Electrolyser ratio of $6: 1$. Therefore, considering the 10MW Electrolyser-based system, a Wind Farm of 60MW as installed power is required.

\subsection{Main assumptions}

The main technical and economic assumptions for the different plant sections are reported in Tables 1 and 2 respectively. If the wind farm is already installed, the main assumptions for the thermodynamic calculations are related to the hydrogen production section (PEM electrolysers) and the synthesis of ammonia/methanol, including gas compression, heat exchangers, reactors, and distillation units. For electrolysers, PEM pressurised modules operating at 30 bar are considered: the main assumptions related to their energy consumption, lifetime, CAPEX, and OPEX are derived from recent literature [10][24][25][26]. Recent studies confirmed that, although alkaline electrolysers are still the cheapest solution, PEM electrolysers cost has recently decreased in a considerable way, making them a feasible option, also considering some important advantages related to their compactness and their fast response to load variations [24][25]. From the economic standpoint, the drawback of PEM electrolysers is related to their lower lifetime, meaning that stack replacement must be considered, with a consequent cost increase of about $50 \%$.

Regarding the methanol and ammonia synthesis units the operating temperature and pressure values are taken from literature and are referred to the well-known traditional plants, while energy consumptions have been estimated from the authors in previous research works for methanol [8][10][15] and from literature data for ammonia [16][17][27]. In both cases, it is worth noting that electrical energy consumption for fuel synthesis is a limited value (3-5\%) compared to the PEM electrolysers consumption, which represents the most important voice. In the case of ammonia, the required temperature and pressure are higher, thus the assumed energy consumption slightly increases too. From the economic point of view, $\mathrm{CO}_{2}$ and $\mathrm{N}_{2}$ contributions cannot be neglected, as considerable amounts are needed for reactions (1) and (2): in stoichiometric conditions, methanol synthesis requires $7.33 \mathrm{~kg} \mathrm{CO}_{2} / \mathrm{kg}$ $\mathrm{H}_{2}$, while ammonia requires $4-67 \mathrm{~kg} \mathrm{~N} / \mathrm{kg} \mathrm{H}$. The related purchasing prices are $15 /$ ton $_{\mathrm{CO} 2}$ [10] and $10 € /$ ton $_{\mathrm{N} 2}$ [29], respectively, Market values are reported in Table 2.

Table 1. Main technical assumptions

\begin{tabular}{|c|c|c|}
\hline \multicolumn{3}{|c|}{ TECHNICAL ASSUMPTIONS } \\
\hline Plant lifetime & 20 & years \\
\hline Plant availability & $95 \%$ & \\
\hline \multicolumn{3}{|l|}{ Electrolysers } \\
\hline PEM nominal power & 10 & MW \\
\hline Operating pressure & 30 & bar \\
\hline Specific energy consumption & 4.7 & $\mathrm{kWh} / \mathrm{Nm}^{3}$ \\
\hline Stack replacement & 80000 & heq \\
\hline \multicolumn{3}{|l|}{ Methanol Unit } \\
\hline Operating temperature & 210 & ${ }^{\circ} \mathrm{C}$ \\
\hline Operating pressure & 80 & bar \\
\hline $\mathrm{H}_{2}: \mathrm{CO}_{2}$ molar ratio & $3: 1$ & \\
\hline Single pass conversion & 0.36 & \\
\hline Overall Conversion & 0.98 & \\
\hline El. Energy consumption auxiliaries & $3 \%$ & PEM cons \\
\hline \multicolumn{3}{|l|}{ Ammonia Unit } \\
\hline Operating temperature & 450 & ${ }^{\circ} \mathrm{C}$ \\
\hline Operating pressure & 200 & bar \\
\hline $\mathrm{H}_{2}: \mathrm{N}_{2}$ molar ratio & $3: 1$ & \\
\hline Single pass conversion & 0.25 & \\
\hline Overall Conversion & 0.95 & \\
\hline El. Energy consumption auxiliaries & $5 \%$ & PEM cons \\
\hline
\end{tabular}

Table 2. Main economic assumptions

\begin{tabular}{|l|c|c|}
\hline \multicolumn{3}{|c|}{ ECONOMIC ASSUMPTIONS } \\
\hline WACC & $6 \%$ & \\
\hline El. energy cost & 0.05 & $€ / \mathrm{kWh}$ \\
\hline Electrolysers & 1000 & $€ / \mathrm{kW}$ \\
\hline CAPEX & $50 \%$ of CAPEX & \\
\hline Stack replacement & 1 & \\
\hline N. Stack replacement & 45 & $€ / \mathrm{kW}$ \\
\hline OPEX & $26548\left(\mathrm{M}_{\text {prod }}\right)^{0.65}$ & $€$ \\
\hline Methanol Unit & $2 \%$ of CAPEX & \\
\hline CAPEX & 15 & $€ /$ ton \\
\hline OPEX & \multicolumn{2}{|}{} \\
\hline CO2 cost & $50890\left(\mathrm{M}_{\text {prod }}\right)^{0.65}$ & $€$ \\
\hline Ammonia Unit & $2 \%$ of CAPEX & \\
\hline CAPEX & 10 & $€ /$ ton \\
\hline OPEX &
\end{tabular}


In order to evaluate and compare the economic feasibility of both P2L systems, the following parameter are considered:

- Annual Fixed Costs (AFC) are calculated as the annual rate of Total Capital Investment (TCI) over 20 years of plant lifetime (n), using a $6 \%$ of WACC [28] as rate (r), as follow:

$$
A F C=T I C * \frac{r *(1+r)^{n}}{(1+r)^{n}-1}
$$

- Annual Variable Costs (AVC) include the sum of the OPEX of each plant component, $\mathrm{CO}_{2}$ and $\mathrm{N}_{2}$ costs, and electrical energy cost.

$$
\begin{gathered}
A V C=\sum_{i} \mathrm{OPEX}_{i}+\mathrm{CO}_{2} \operatorname{cost}+\mathrm{N}_{2} \cos t+ \\
\text { El.Energy cost [€] }
\end{gathered}
$$

- Fuel Production Cost (FPC) is the specific cost of the product over the total annual costs. It is calculated in terms of (i) the amount of product (€/ton), (ii) the energy content in the product (€/MWh), (iii) the amount of $\mathrm{H} 2$ contained in the product, as follows:

$$
F P C_{€ / \text { ton }}=\frac{A F C+A V C}{\text { Annual Production }[\text { ton }]}
$$

$$
\begin{aligned}
F P C_{€ / M W h} & =\frac{A F C+A V C}{\text { Annual Prod. energy content }[M W h]} \\
F P C_{€ / M W h} & =\frac{A F C+A V C}{\text { Annual Prod. } \mathrm{H} 2 \text { content }\left[\mathrm{kg} \mathrm{of} \mathrm{H}_{2}\right]}
\end{aligned}
$$

The effect on the FPC of the oxygen sale is considered by subtracting the annual revenues of the $\mathrm{O} 2$ selling from the annual costs (numerator)

\section{Results}

The two plant configurations are compared from the technical and economic standpoints: in particular, the global efficiency is considered as the main parameter to compare the two solutions from the technical point of view, while average production costs are calculated in order to evaluate economic feasibility.

\subsection{Energy efficiency comparison}

The energy efficiency of the two $\mathrm{P} 2 \mathrm{~L}$ processes is calculated as the ratio between the total energy content of the produced chemical (methanol/ammonia) and the energy consumption for the whole process. Fig. 3 shows the Sankey diagram for the two processes. In both cases, most of the energy losses are due to PEM electrolysers, which are also responsible for the largest electrical energy consumption (power input of $10 \mathrm{MWh}$, more than $95 \%$ of the total in both cases). Other losses are due to compressors, heat exchangers, and synthesis reactors. Comparing overall efficiencies, it is worth noting that methanol synthesis presents a higher value $(52.1 \%)$. In the case of ammonia synthesis $(49.8 \%)$, the
Haber-Bosch process occurs at higher pressures and temperatures; therefore, a higher energy amount is required and efficiency results to be slightly lower than in the case of methanol synthesis.

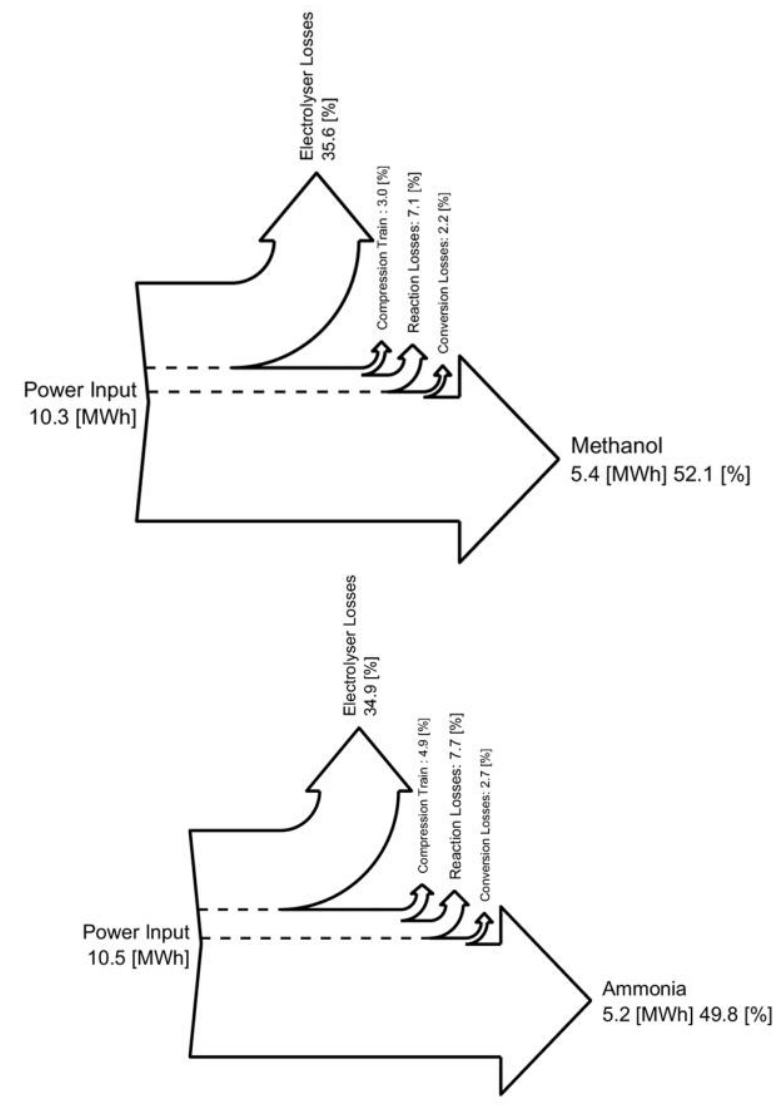

Fig. 3. Energy efficiency for methanol (above) and ammonia (below) synthesis

Considering plant operability of $95 \%$ (corresponding to about 8320 equivalent hours per year), the energy inputs are 85.8 and $87.6 \mathrm{GWh} /$ year to produce respectively 8100 ton/year of methanol and 8510 ton/year of ammonia. In both cases, the largest energy consumption is due to PEM electrolysers ( $83 \mathrm{GWh} /$ year). In the case of methanol production, about 11,600 ton/year are employed for the synthesis process, while in the case of ammonia, about 7400 ton/year are required. Despite the two produced fuels are nearly the same in terms of mass flows and energy amount, the $\mathrm{H}_{2}$ content is about $50 \%$ higher in the case of ammonia (1502 ton/year vs 1012 ton/year), confirming the interest of this chemical as a hydrogen carrier. In both configurations, the electrolysers co-produce also a not negligible amount of pure Oxygen (12,600 ton/year), which could be stored and sold to industrial users on the market.

\subsection{Economic results}

As first, the total capital cost was determined by using the cost functions reported in Table 2. The capital cost of P2M and P2A systems, both based on a 10MW electrolyser, resulted in around 17.3M€ and 19.6 M€, respectively. Most of these costs (15 M€) is due to electrolysers, including stack replacement. Figure 4 reports the distribution of annual fixed and variable 
costs, which are quite similar for the two configurations. It is possible to note how the cost of electricity is the predominant voice in both cases, accounting more than $65 \%$. The second item in terms of importance is the electrolyser, accounting for about $27 \%$. All the other costs, including the methanol unit $(3 \%)$ and ammonia unit $(6 \%)$, count for no more than $10 \%$. It is clear that the affordability and the technology readiness level of both wind turbine and electrolyser technologies play a crucial role in the economic viability of the P2L system. Regarding the synthesis units, ammonia results more expensive than methanol, mostly due to the higher operating pressure and temperature and to the lower single-pass conversion that imposes a higher recirculation ratio.

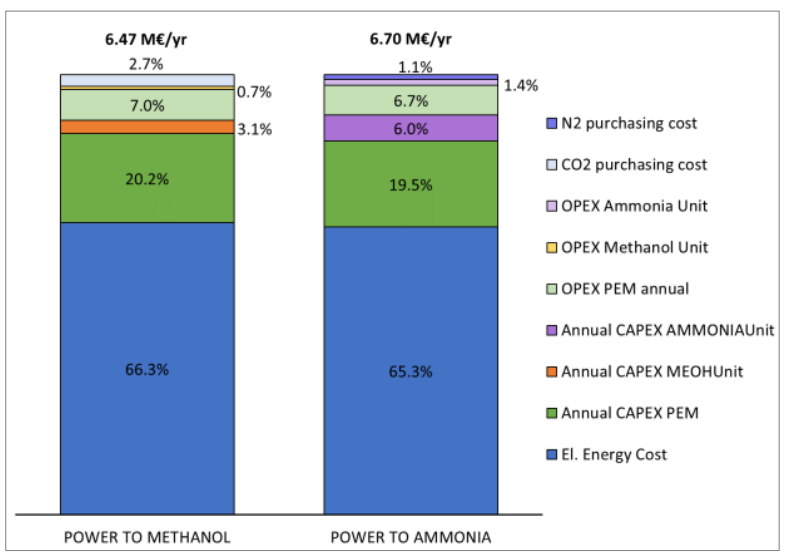

Fig. 4. Annual costs comparison for Power-to-Methanol and Power-to-Ammonia plants

From the annual total costs, it is possible to calculate the methanol/ammonia production costs. Tab. 3 reports production costs referred to three different voices: a ton of synthesized chemical, MWh of energy content in the chemical, and $\mathrm{kg} \mathrm{H}_{2}$ stored in the chemical.

Table 3. Production costs for methanol and ammonia

\begin{tabular}{|c|c|c|c|}
\hline & & $\begin{array}{l}\text { Methanol } \\
\text { Production } \\
\text { Cost }\end{array}$ & $\begin{array}{c}\text { Ammonia } \\
\text { Production } \\
\text { Cost }\end{array}$ \\
\hline $\begin{array}{c}\text { No } \\
\text { O2 sale }\end{array}$ & $\begin{array}{l}€ / \text { ton } \\
€ / \mathrm{MWh} \\
€ / \mathrm{kgH} 2 \mathrm{cont}\end{array}$ & $\begin{array}{c}799.2 \\
144.6 \\
6.4\end{array}$ & $\begin{array}{c}787.5 \\
152.0 \\
4.5\end{array}$ \\
\hline $\begin{array}{c}\text { O2 sale } \\
\text { @100€/ton }\end{array}$ & $\begin{array}{l}€ / \text { ton } \\
€ / \mathrm{MWh} \\
€ / \mathrm{kg} \mathrm{H} 2\end{array}$ & $\begin{array}{c}642.9 \\
116.3 \\
5.1\end{array}$ & $\begin{array}{c}638.9 \\
123.3 \\
3.6\end{array}$ \\
\hline $\begin{array}{c}\mathrm{O} 2 \text { sale } \\
@ 150 € / \text { ton }\end{array}$ & $\begin{array}{l}€ / \text { ton } \\
€ / \mathrm{MWh} \\
€ / \mathrm{kgH} 2 \mathrm{cont}\end{array}$ & $\begin{array}{c}564.8 \\
102.2 \\
4.5\end{array}$ & $\begin{array}{c}564.6 \\
109.0 \\
3.2\end{array}$ \\
\hline $\begin{array}{c}\text { O2 sale } \\
\text { @2 } 200 € / \text { ton }\end{array}$ & $\begin{array}{l}€ / \text { ton } \\
€ / \mathrm{MWh} \\
€ / \mathrm{kgH} 2 \mathrm{cont}\end{array}$ & $\begin{array}{c}486.7 \\
88.0 \\
3.9\end{array}$ & $\begin{array}{c}490.3 \\
94.6 \\
2.8\end{array}$ \\
\hline
\end{tabular}

The values reported in Tab. 3 consider different options in terms of $\mathrm{O}_{2}$ selling. In the first case, $\mathrm{O}_{2}$ co-produced in the PEM electrolysers is vented to the atmosphere, while in the other cases it is stored and sold to industrial users located close to the production plant, at different market prices. This sensitivity analysis is performed in order to evaluate the influence of $\mathrm{O}_{2}$ selling in terms of feasibility comparison of the two solutions. From the results reported in Tab. 3 , it is possible to note that production costs in $€ /$ ton are nearly the same; in terms of $€ / \mathrm{kg} \mathrm{H}$ ammonia shows its superiority as a hydrogen carrier also from the economic standpoint.

\section{Conclusions}

In this study, two P2F solutions (ammonia and methanol) from renewable wind energy have been investigated and compared from technic and economic standpoints. The energy analysis has been performed considering energy efficiency: the solutions show similar values, as the largest source of irreversibility and energy consumption is due to electrolysers, which are common in both configurations. P2M has an efficiency of about $52 \%$, while P2A presents a lower value (50\%) due to higher energy consumption in compressors.

From the economic standpoint, the solutions do not present a great difference, as the most important voices of costs are related to electrical energy purchasing and electrolysers CAPEX, which are common to the two configurations. Ammonia shows its superiority compared to methanol as a hydrogen carrier, as it can store a considerable amount of $\mathrm{H}_{2}$ in its structure. On the other hand, methanol production with the described process allows for the utilization of a considerable amount of $\mathrm{CO}_{2}$, with a positive impact in environmental terms. Finally, it is worth noting that, although production costs are higher than the market values of $\mathrm{NH}_{3}$ and $\mathrm{MeOH}$, the option of selling the co-produced $\mathrm{O}_{2}$, together with a reduction of PEM electrolysers capital costs can considerably improve the economic feasibility of both the solutions.

\section{References}

1. https://www.iea.org/statistics/, International Energy Agency (IEA) official website, last access 28/7/2020.

2. https://ec.europa.eu/energy/topics/energystrategy/clean-energy-all-europeans_en, European Commission official website, last access 28/7/2020.

3. Ferrari M., Rivarolo M., Massardo A.F., Hydrogen production system from photovoltaic panels: experimental characterization and size optimization, En. Conv. and Man., 116 (2016), 194-202.

4. Bellotti D., Rivarolo M., Magistri L., Massardo A.F., Thermo-economic comparison of hydrogen and hydro-methane produced from hydroelectric energy for land transportation, Int. J. Hydrogen En., 2015 (40), 2433-2444.

5. Barthelemy, H.; Weber, M.; Barbier, F. Hydrogen storage: Recent improvements and industrial perspectives, Int. J. Hydrogen En., 42 (2017), 7254-7262.

6. Moradi R., Groth K.M., Hydrogen storage and delivery: Review of the state of the art 
technologies and risk and reliability analysis, Int. J. Hydrogen En., 44 (2019), 12254-12269.

7. Proost J., State-of-the art CAPEX data for water electrolysers, and their impact on renewable hydrogen price settings, Int. J. Hydrogen En., 44 (2019), 4406-4413.

8. D. Bellotti, M. Rivarolo, L. Magistri, Economic feasibility of methanol synthesis as a method for CO2 reduction and energy storage, En. Proc., 158 (2019), 4721-4728.

9. American Bureau of Shipping (ABS), setting the course to low carbon shipping (2019).

10. Bellotti D., Sorce A., Rivarolo M., Magistri L., Techno-economic analysis for the integration of a power to fuel system with a CCS coal power plant, J. CO2 Utilization, 33 (2019), 262-272.

11. Andersson J., Lundgren J., Techno-economic analysis of ammonia production via integrated biomass gasification, App. En., 130(2014), 484490.

12. A. Klerke, C.H. Christensen, J.K. Norskov, T. Vegge, Ammonia for hydrogen storage: challenges and opportunities, J. Mater. Chem., 2008, 18, 2304-2310.

13. K.E. Lamb, M.D. Dolan, D.F. Kennedy, Ammonia for hydrogen storage; A review of catalytic ammonia decomposition and hydrogen separation and purification, Int. J. of Hydrogen En., 2019, 44, 3580-3593. DOI: 10.1016/j.ijhydene.2018.12.024

14. Rivarolo M., Riveros-Godoy G., Magistri L., Massardo A.F., Clean hydrogen and ammonia synthesis in Paraguay from Itaipu $14 \mathrm{GW}$ hydroelectric plant, ChemEngineering, 3 (2019), 111.

15. D. Bellotti, L. Cassettari, M. Mosca, L. Magistri, RSM approach for stochastic sensitivity analysis of the economic sustainability of a methanol production plant using renewable energy sources, J. Clean. Prod., vol. 240, p. 117947, 2019, doi: 10.1016/j.jclepro.2019.117947.

16. Zhang H., Wang L., Van Herle J., Maréchal F., Desideri U., Techno-economic comparison of green ammonia production processes, App. En., 259 (2020), 114135.

17. Morgan E.R., Techno-economic feasibility study of ammonia plants powered by off-shore wind, 2013, Open Access Dissertations, 697.

18. S. Szima and C. C. Cormos, Improving methanol synthesis from carbon-free $\mathrm{H} 2$ and captured $\mathrm{CO} 2$ : A techno-economic and environmental evaluation, J. CO2 Util., vol. 24, no. February, pp. 555-563, 2018,

19. Sanchez A., \& Matin M., Optimal renewable production of ammonia from water and air, Journal of Cleaner Production 178 (2018), 325-342

20. Tunå P. , Hulteberg C. , Ahlgren S. Technoeconomic assessment of nonfossil ammonia production, Environ. Prog. Sustainable Energy, 2014 (33), 1290-1297. doi:10.1002/ep.11886
21. Bicer Y., Dincer I., Vezina G., Raso F., Impact Assessment and Environmental Evaluation of Various Ammonia Production Processes, Environmental Management, 2017 (59), 842-855. https://doi.org/10.1007/s00267-017-0831-6

22. Al-Breiki M., Bicer Y., Technical assessment of liquefied natural gas, ammonia and methanol for overseas energy transport based on energy and exergy analyses, Int. J. of Hydrogen En., 2020.

23. Rivarolo M, Improta O., Magistri L., Panizza M., Barbucci A., Thermo-economic analysis of a hydrogen production system by sodium borohydride (NaBH4), Int. J. Hydrogen En., 43 (2018), 1606-1614.

24. Schmidt O., Gambhir A., Staffell I., Hawkes A., Nelson J. and Few S., Future cost and performance of water electrolysis: An expert elicitation study, Int. J. Hydrogen En., 42 (2017), 30470-30492.

25. Proost J., State-of-the art CAPEX data for water electrolysers, and their impact on renewable hydrogen price settings, Int. J. Hydrogen En., 44 (2019), 4406-4413.

26. Thomas, D., Cost reduction potential for electrolyser technology, EU Power-to-Gas Platform

27. Institute for Sustainable Process Technology, Power to Ammonia, final report.

28. http://www.waccexpert.com, last access 28/7/2020.

29. https://www.peakscientific.com/nitrogen-gascosts-genius-xe/, last access 30/9/2020. 